\title{
Predictors of Glycemic Control among Patients with Type 2 Diabetes in Najran Armed Forces Hospital: A Pilot Study
}

\author{
Imed Harrabi ${ }^{*}$, Fawaz Al Harbi ${ }^{2}$, Saad Al Ghamdi ${ }^{1}$ \\ ${ }^{1}$ Department of Family and Community Medicine, Najran Armed Forces Hospital, Najran, KSA \\ ${ }^{2}$ Department of Internal Medicine, Najran Armed Forces Hospital, Najran, KSA \\ Email: ${ }^{*}$ imed harrabi@yahoo.fr
}

Received 10 April 2014; revised 8 May 2014; accepted 15 May 2014

Copyright $(\underset{2014}{ } 20 y$ authors and Scientific Research Publishing Inc.

This work is licensed under the Creative Commons Attribution International License (CC BY). http://creativecommons.org/licenses/by/4.0/

(c) $\underset{\mathrm{EY}}{\mathrm{i}}$ Open Access

\section{Abstract}

Background: Diabetes mellitus is a serious condition with potentially devastating complications that affects all age groups worldwide. The purposes of this study are to describe the glycemic control levels and to determine the associated factors of poor glycemic control among type 2 diabetes patients followed in Najran Armed Forces Hospital. Methods: We conducted a retrospective analysis of administrative data from adult patients with diabetes type 2 followed in NAFH clinics. To be included in the pilot study, patients needed to meet the following criteria: 1) Be identified as having diabetes type 2 using algorithms employed by disease management oasis program; 2) Be at least aged 18; 3) Be male or female; 4) Have Fasting Plasma Glucose (FPG) and HbA1c measured at least twice during the last year. Both univariate and multivariate approaches of logistic regression were applied to determine factors associated with poor glycemic control. Results: Data from a total of 100 patients were analyzed. There were $22 \%$ of patients that achieved glycemic control. The risk factors associated with poor glycemic control were being female, age < 65 years old and those who had not achieved the target total cholesterol. Conclusion: The findings of this study showed that diabetic control is suboptimal. This study provides factors that predict poor glycemic control. With this information, subgroups with high risk of disease morbidity were identified. Barriers that prevent these patients from meeting their goals must be explored to improve health outcomes.

\section{Keywords}

Glycemic Control, Diabetes Type 2, Adults

\footnotetext{
${ }^{*}$ Corresponding author.
}

How to cite this paper: Harrabi, I., Al Harbi, F. and Al Ghamdi, S. (2014) Predictors of Glycemic Control among Patients with Type 2 Diabetes in Najran Armed Forces Hospital: A Pilot Study. Journal of Diabetes Mellitus, 4, 141-147. 


\section{Introduction}

Diabetes mellitus (DM) is now considered one of the most common non-communicable diseases worldwide [1] [2]. It is highly prevalent for all age groups worldwide [3]. It is estimated that the number of people with diabetes worldwide was about 366 million in 2011 and will increase to 552 million in 2030 [4]. According to the International Diabetes Federation's (IDF) statistics released $75 \%$ of that figure will be from developing countries [3]. Five of the top ten countries estimated to have the highest prevalence of diabetes are from the Middle East and North Africa region (MENA).

Since the Diabetes Control and Complication Trial and the United Kingdom Prospective Diabetes Study demonstrated that excellent Glycemic control reduces Microvascular complications in types 1 and 2 diabetes mellitus, respectively [5] [6], Glycated hemoglobin has become an increasingly important measure of Glycemic control. Despite the strong consensus that excellent Glycemic control improves Microvascular outcomes in type 2 diabetes mellitus [7], there are limited numbers of patients with diabetes who can obtain good Glycemic control. $[8]$.

International studies showed that more than two thirds of diabetic patients did not achieve target HbA1C level

At the national level, a recent study was conducted in Saudi Arabia in which only 27\% of the study patients reached the target HBA1C of $<7 \%$ [9]. Another study in primary care clinics showed similar results as only $24 \%$ of the patients achieved a HBA1C level of $<7 \%$ [10]. Therefore the current study was conducted to evaluate Glycemic control and its main predictors among diabetic patient's type 2 at the NAFH.

\section{Methods}

\subsection{Study Design}

We conducted a retrospective analysis of administrative data from adult patients with diabetes type 2 followed in NAFH clinics.

\subsection{Studied Population}

A sample of 100 patients was randomly selected among eligible diabetic patients type 2 . To be included in the pilot study, patients needed to meet the following criteria:

- Be identified as having diabetes type 2 using algorithms employed by disease management oasis program;

- Be at least aged 18;

- Male or female;

- Have Fasting Plasma Glucose (FPG) and HbA1c measured at least twice during the last year.

\subsection{Definition of the Main Variables}

- For each patient, we calculated mean of the two last HbA1c levels. We grouped patients into 2 categories according to the recent recommendation of the Canadian Diabetes Association [11]:

o Controlled, those who achieved and maintained a mean HbA1c $\leq 7 \%$.

o Not controlled, those who had a mean HbA1c higher than 7\%.

- Medicines used for glucose control were categorized into three levels:

o Insulin alone,

o Oral agents alone, and

o Insulin with oral agents.

- Clinical characteristics considered were systolic (SBP) and diastolic (DBP) blood pressure, total and HDL cholesterol, weight and height.

- According to their smoking status, patients were grouped into two categories: smokers and non smokers.

- Hypertension was considered SBP or DBP greater than or equal to $130 \mathrm{~mm} \mathrm{Hg}$ and $80 \mathrm{~mm} \mathrm{Hg}$, respectively. Total cholesterol or HDL greater than equal to $200 \mathrm{mg} / \mathrm{dl}$ and $45 \mathrm{mg} / \mathrm{dl}$, respectively were defined as non controlled.

\subsection{Statistical Analysis}

Data were entered and analyzed using Statistical Package for Social Science program: S.P.S.S 17.0. 
The Chi square test was used to evaluate the relationships between qualitative variables. A p value less than $5 \%$ was considered as significant.

Separate multivariable logistic regression models were used to identify the main predictors of poor glycemic control. A p value less than $5 \%$ was considered as significant for independent variables in the final model.

\section{Results}

\subsection{General Characteristics}

Table 1 shows the study population characteristics. About $70 \%$ of patients were older than 50 years old with a mean age of $58 \pm 14.52$ years $(55.6 \pm 16.31$ years among males vs $59.48 \pm 12.33$ years among females; $\mathrm{p}=$ $0.18)$.

\subsection{Health Status}

The levels of systolic and diastolic blood pressures were respectively less than 130 and $80 \mathrm{~mm} \mathrm{Hg}$, in respectively $70 \%$ and $72 \%$ of the study population. Mean total cholesterol was $174 \mathrm{mg} / \mathrm{dl}$ and those with lower total cholesterol (less than $200 \mathrm{mg} / \mathrm{dl}$ ) had non statistical significant lower mean A1C values (8.53\%) than those with higher total cholesterol levels (8.85\%) (Table 2).

The total cholesterol level was normal in more than $72 \%$ of patients while HDL cholesterol was normal in only $44 \%$ of patients (Table 2).

About 30\% of the patient's systolic blood pressure was not controlled and in $28 \%$ of patients the diastolic blood pressure was above the target level (Table 2).

\subsection{Glycemic Control}

The overall Glycemic control was evaluated through measurement of $\mathrm{Hb} \mathrm{A} 1 \mathrm{C}$ as it was mentioned previously, which was acceptable in $22 \%$ of the patients. The level of Glycemic control was better among: males, patients aged more than 65 years, normal systolic and/or diastolic blood pressure, normal total cholesterol levels and patients who take oral treatments (Table 3).

\subsection{Predictors of Non Glycemic Control}

A total of $78 \%$ of patients were non controlled regarding their diabetes. Table 4 provides the results of Univariate logistic regression analysis which illustrates the non-adjusted factors associated with non Glycemic control. The risk of non Glycemic control was higher but with no statistical significance among females (OR = 1.26; CI95\% $=(0.49-3.26))$. Compared to patients with normal blood pressure (systolic and /or diastolic), patients with high blood pressure were non significantly more likely to have non glycemic control (OR $=1.12$; CI95\% $=$ $(0.40$ - 3.09) for SBP; OR $=1.42$; CI95\% $=(0.47$ - 4.31) for DBP $)$. Patients taking insulin treatment were more likely to have poor control compared with patients taking oral medications $(\mathrm{OR}=2.81$; CI95\% $=(0.76-10.42))$. Similarly, patients with low level of HDL cholesterol were non significantly more likely to have non glycemic control $(\mathrm{OR}=2.21$; CI95\% $=(0.84-5.82))$. Compared with older patients, those aged less than 65 years were significantly more likely to have poor control $(\mathrm{OR}=2.99$; CI95\% $=(1.10-8.10))$ and patients with high levels of total cholesterol were statistically associated with non Glycemic control $(\mathrm{OR}=4.90$; CI95\% $=(1.1-22.64))$. In the final multivariate logistic regression model, only age less than 65 years and high levels of total cholesterol were statistically associated with non Glycemic control (Table 5).

\section{Discussion}

The adequacy of Glycemic control in diabetes mellitus is a cornerstone in reducing morbidity and mortality of the disease [12] [13]. More than two thirds of the patients in the present study were not adequately controlled and this represents a serious problem because diabetes is a very prevalent disease (23\%) in the Saudi community [14]. The poor level of Glycemic control is a common phenomenon among Saudi diabetic patients. A recent study was conducted in Saudi Arabia at a national level including 28 health centers all over the Kingdom of Saudi Arabia in which only $27 \%$ of the study patients reached the target of HbA1C of $<7 \%$ [9]. In our study, this high rate of non controlled patients could be explained in part by the non observance of the prescribed treatment. 
Table 1. Distribution of HbA1C according to general and biological data among the studied population.

\begin{tabular}{|c|c|c|}
\hline VARIABLE & NUMBER & PERCENTAGE \\
\hline \multicolumn{3}{|c|}{ GENDER $(\mathrm{n}=100)$} \\
\hline Male & 50 & 50 \\
\hline Female & 50 & 50 \\
\hline \multicolumn{3}{|l|}{$\operatorname{AGE}(n=100)$} \\
\hline$<50$ & 28 & 28 \\
\hline $50-65$ & 39 & 39 \\
\hline$>65$ & 33 & 33 \\
\hline \multicolumn{3}{|c|}{ TREATMENT $(\mathrm{n}=100)$} \\
\hline Oral & 73 & 73 \\
\hline Insulin & 27 & 27 \\
\hline \multicolumn{3}{|c|}{ MARITAL STATUS $(\mathrm{n}=94)$} \\
\hline Married & 92 & 97.9 \\
\hline Single & 2 & 2.1 \\
\hline \multicolumn{3}{|c|}{ SMOKING STATUS $(\mathrm{n}=40)$} \\
\hline Smoker & 04 & 10 \\
\hline Non smoker & 36 & 90 \\
\hline \multicolumn{3}{|c|}{ NUMBER OF VISITS DURING THE LAST YEAR $(\mathrm{n}=$ 96) } \\
\hline$\leq 3$ & 70 & 72.9 \\
\hline$>3$ & 26 & 27.1 \\
\hline
\end{tabular}

Table 2. Distribution of HbA1C according to general and biological data among the studied population.

\begin{tabular}{|c|c|c|c|}
\hline VARIABLE & NUMBER (\%) & $\operatorname{MEAN}(\mathrm{A} 1 \mathrm{C} \pm \mathrm{SD})$ & $\mathrm{p}$ \\
\hline \multicolumn{4}{|l|}{ GENDER } \\
\hline Male & $50(50)$ & $8.59 \pm 1.99$ & \multirow{2}{*}{0.74} \\
\hline Female & $50(50)$ & $8.71 \pm 1.81$ & \\
\hline \multicolumn{4}{|l|}{ AGE } \\
\hline$<50$ & $28(28)$ & $8.97 \pm 2.23$ & \multirow{3}{*}{0.17} \\
\hline $50-65$ & 39 (39) & $8.83 \pm 1.53$ & \\
\hline$>65$ & $33(33)$ & $8.14 \pm 1.91$ & \\
\hline \multicolumn{4}{|l|}{ TREATMENT } \\
\hline Oral & $73(73)$ & $8.42 \pm 1.79$ & \multirow{2}{*}{0.05} \\
\hline Insulin & $27(27)$ & $9.25 \pm 2.04$ & \\
\hline \multicolumn{4}{|c|}{ NUMBER OF VISITS DURING THE LAST YEAR } \\
\hline$\leq 3$ & $70(72.9)$ & $8.36 \pm 1.89$ & \multirow{2}{*}{0.01} \\
\hline$>3$ & $26(27.1)$ & $9.48 \pm 1.75$ & \\
\hline \multicolumn{4}{|l|}{ SBP (mmHg) } \\
\hline$<130$ & $70(70)$ & $8.69 \pm 1.93$ & \multirow{2}{*}{0.74} \\
\hline$\geq 130$ & $30(30)$ & $8.55 \pm 1.79$ & \\
\hline \multicolumn{4}{|l|}{ DBP (mmHg) } \\
\hline$<80$ & $72(72)$ & $8.58 \pm 2.00$ & \multirow{2}{*}{0.58} \\
\hline$\geq 80$ & $28(28)$ & $8.81 \pm 1.58$ & \\
\hline \multicolumn{4}{|c|}{ TOTAL CHOLESTEROL (mg/dL) } \\
\hline$<200$ & $74(72.4)$ & $8.53 \pm 2.08$ & \multirow{2}{*}{0.46} \\
\hline$\geq 200$ & $27(27.6)$ & $8.85 \pm 1.27$ & \\
\hline \multicolumn{4}{|l|}{ HDL (mg/dL) } \\
\hline$\leq 45$ & $55(56.1)$ & $8.82 \pm 1.81$ & \multirow{2}{*}{0.23} \\
\hline$>45$ & 43 (43.9) & $8.36 \pm 1.98$ & \\
\hline
\end{tabular}


Table 3. Distribution of the studied population according to their glycemic control status (controlled Hba1c $\leq 7 \%$, uncontrolled Hbalc > 7\%).

\begin{tabular}{|c|c|c|c|c|c|}
\hline \multirow{2}{*}{ HBA1C } & \multicolumn{2}{|c|}{$\leq 7 \%$} & \multicolumn{2}{|c|}{$>7 \%$} & \multirow[t]{2}{*}{$\mathrm{p}$} \\
\hline & $\mathrm{n}$ & $\%$ & $\mathrm{n}$ & $\%$ & \\
\hline \multicolumn{6}{|c|}{ GENDER $(n=90)$} \\
\hline Male & 12 & 24.0 & 38 & 76.0 & \multirow{2}{*}{0.62} \\
\hline Female & 10 & 20.0 & 40 & 80.0 & \\
\hline \multicolumn{6}{|c|}{$\operatorname{AGE}(\mathrm{n}=90)$} \\
\hline$<65$ & 10 & 37.0 & 17 & 63 & \multirow{2}{*}{0.02} \\
\hline$\geq 65$ & 12 & 16.4 & 62 & 83.6 & \\
\hline \multicolumn{6}{|c|}{ TREATMENT $(\mathrm{n}=100)$} \\
\hline Oral & 19 & 26.0 & 54 & 74 & \multirow{2}{*}{0.11} \\
\hline Insulin & 03 & 11.1 & 24 & 88.9 & \\
\hline \multicolumn{6}{|c|}{ SBP $(m m H g)(n=100)$} \\
\hline$<130$ & 15 & 21.4 & 55 & 78.6 & \multirow{2}{*}{0.83} \\
\hline$\geq 130$ & 07 & 23.3 & 23 & 76.7 & \\
\hline \multicolumn{6}{|c|}{ DBP $(m m H g)(n=100)$} \\
\hline$<80$ & 17 & 23.6 & 55 & 76.4 & \multirow{2}{*}{0.53} \\
\hline$\geq 80$ & 05 & 17.9 & 23 & 82.1 & \\
\hline \multicolumn{6}{|c|}{ TOTAL CHOLESTEROL (mg/dL) $(\mathrm{n}=98)$} \\
\hline$<200$ & 20 & 28.2 & 51 & 71.8 & \multirow{2}{*}{0.02} \\
\hline$\geq 200$ & 02 & 7.4 & 25 & 92.6 & \\
\hline \multicolumn{6}{|c|}{ HDL (mg/dL) $(n=98)$} \\
\hline$\leq 45$ & 09 & 16.4 & 46 & 83.6 & \multirow{2}{*}{0.10} \\
\hline$>45$ & 13 & 30.2 & 30 & 69.8 & \\
\hline
\end{tabular}

Table 4. Factors associated with poor Glycemic control: univariate analysis.

\begin{tabular}{|c|c|c|}
\hline VARIABLE & OR & CI95\% \\
\hline \multicolumn{3}{|l|}{ GENDER } \\
\hline Male & 1 & \\
\hline Female & 1.26 & $(0.49-3.26)$ \\
\hline \multicolumn{3}{|l|}{ AGE } \\
\hline$\geq 65$ & 1 & \\
\hline$<65$ & 2.99 & $(1.10-8.10)$ \\
\hline \multicolumn{3}{|l|}{ TREATMENT } \\
\hline Oral & 1 & \\
\hline Insulin & 2.81 & $(0.76-10.42)$ \\
\hline \multicolumn{3}{|l|}{ SBP (mmHg) } \\
\hline$<130$ & 1 & \\
\hline$\geq 130$ & 1.12 & $(0.40-3.09)$ \\
\hline \multicolumn{3}{|l|}{ DBP (mmHg) } \\
\hline$<80$ & 1 & \\
\hline$\geq 80$ & 1.42 & $(0.47-4.31)$ \\
\hline \multicolumn{3}{|c|}{ TOTAL CHOLESTEROL (mg/dL) } \\
\hline$<200$ & 1 & \\
\hline$\geq 200$ & 4.90 & $(1.1-22.64)$ \\
\hline \multicolumn{3}{|l|}{ HDL (mg/dL) } \\
\hline$\leq 45$ & 1 & \\
\hline$>45$ & 2.21 & $(0.84-5.82)$ \\
\hline
\end{tabular}


Table 5. Factors associated with poor Glycemic control: Multivariate analysis.

\begin{tabular}{ccc}
\hline VARIABLE & OR & CI95\% \\
\hline GENDER & & $(0.53-4.11)$ \\
Male & 1 & \\
Female & 1.48 & $(1.26-10.87)$ \\
AGE & & \\
$\geq 65$ & 1 & \\
$<65$ & 3.71 & $(1.26-29.47)$ \\
TOTAL CHOLESTEROL (g/dL) & 1 & \\
$<200$ & 6.08 & \\
\hline
\end{tabular}

This issue should be explored by further studies to estimate the real rate of observance and its main determinants. Glycemic control in males was found to be significantly better than females, and this can be due to the fact that ; females are usually the caregivers for the entire family not only the husband and children but also mothers and mothers in law which may increase their heavy domestic responsibilities. This feature could be a local and regional phenomenon as other studies found that gender was not associated with Glycemic control [15].

In our pilot study, age was found significantly related to Glycemic control and the older age group ( $>65$ years) was better controlled compared to younger patients. The same finding was found in recent studies [16] [17].

This pilot study has some limitations such as poor recording in the charts which were missing some important variables such as level of education, smoking status, body mass index. Another limitation is that Glycemic control can be affected by other factors that were not studied here, such as the duration of diabetes and especially the patient's compliance.

Although the Najran Armed Forces Hospital offers a high standard of medical care, the findings of the present pilot study showed that diabetic control is suboptimal.

\section{Conclusions}

The main results indicate that age and high levels of total cholesterol are predictors for non glycemic control. Patients with these characteristics may need targeted interventions to improve glycemic control. Patients younger than age 65 years should be warned of the health risks of non glycemic control.

There is really a need for further studies to find out the level of patient's compliance and the possible other causes of the poor glycemic control in order to take the necessary and adapted intervention measures.

\section{Acknowledgements}

A special thanks to Mr. Ejaz Saeed Aslam, Mr. Mohammed Rimaz, Ms. Roma Galicia, Ms. Baiali Mutin, all Doctors and nurses of the Internal Medicine Department.

\section{References}

[1] American Diabetes Association (ADA) (2002) Implications of the Diabetes Control and Complications Trial. Diabetes Care, 25, S25-S27. http://dx.doi.org/10.2337/diacare.25.2007.S25

[2] The Diabetes Control and Complications Trial Research Group (1993) The Effect of Intensive Treatment of Diabetes on the Development and Progression of Long-Term Complications in Insulin-Dependent Diabetes Mellitus. New England Journal of Medicine, 329, 977-986. http://dx.doi.org/10.1056/NEJM199309303291401

[3] IDF (2003) International Diabetes Federation: Diabetes Atlas. IDF. http://www.idf.org/sites/default/files/IDF_Diabetes_Atlas_2ndEd.pdf

[4] Whiting, D.R., Guariguata, L., Weil, C. and Shaw, J. (2011) IDF Diabetes Atlas: Global Estimates of the Prevalence of Diabetes for 2011 and 2030. Diabetes Research and Clinical Practice, 94, 311-321. http://dx.doi.org/10.1016/j.diabres.2011.10.029

[5] The Diabetes Control and Complications Trial Research Group (1993) The Effect of Intensive Treatment of Diabetes on the Development and Progression of Long-Term Complications in Insulin-Dependent Diabetes Mellitus. New England Journal of Medicine, 329, 977-986. http://dx.doi.org/10.1056/NEJM199309303291401 
[6] UK Prospective Diabetes Study (UKPDS) (1998) Group. Intensive Blood-Glucose Control with Sulphonylureas or Insulin Compared with Conventional Treatment and Risk of Complications in Patients with Type 2 Diabetes (UKPDS 33). The Lancet, 352, 837-853. http://dx.doi.org/10.1016/S0140-6736(98)07019-6

[7] American Diabetes Association (2002) Implications of the United Kingdom Prospective Diabetes Study. Diabetes Care, 25, 528-532.

[8] Sharon, H., Judith, F. and Catherine, C. (2004) Poor Control of Risk Factors for Vascular Disease among Adults with Previously Diagnosed Diabetes. The Journal of the American Medical Association, 291, 335-342. http://dx.doi.org/10.1001/jama.291.3.335

[9] Al-Elq, A.H. (2009) Current Practice in the Management of Patients with Type 2 Diabetes Mellitus in Saudi Arabia. Saudi Medical Journal, 30, 1551-1556.

[10] Alfadda, A. and Abdulrahman, K. (2006) Assessment of Care for Type 2 Diabetic Patients at the Primary Care Clinics of a Referral Hospital. Journal of Family \& Community Medicine, 13, 13-18.

[11] Canadian Diabetes Association Clinical Practice Guidelines Expert Committee (2013) Target for Glycemic Control. Canadian Journal of Diabetes, 37, S31-S34.

[12] American Diabetes Association (2014) Standards of Medical Care in Diabetes. Diabetes Care, 37, S14-S80. http://dx.doi.org/10.2337/dc14-S014

[13] Sarah, J.B., Soma, S.N., Margaret, J., Jeremy, M., Shiva, S. and Charles, M. (2004) Adequacy of Glycemic, Lipid, and Blood Pressure Management for Patients with Diabetes in a Managed Care Setting. Diabetes Care, 27, 694-698. http://dx.doi.org/10.2337/diacare.27.3.694

[14] Al-Nozha, M.M., Al-Maatouq, M.M., Al-Mazrou, Y.Y., Al-Harth S.S., Arafah, M.R., Khalil, M.Z., et al. (2004) Diabetes Mellitus in Saudi Arabia. Saudi Medical Journal, 25, 1603-1610.

[15] Charpentier, G., Genes, N., Vaur, L., Amar, J., Clerson, P., Cambou, J.P. and Gueret, P. (on Behalf of the ESPOIR Diabetes Study Investigators) (2003) Control of Diabetes and Cardiovascular Risk Factors in Patients with Type 2 Diabetes: A National Wide French Survey. Diabetes \& Metabolism, 29, 152-158. http://dx.doi.org/10.1016/S1262-3636(07)70022-8

[16] Yoshiharu, T., Toshiharu, I., Kana, M., Toru, E. and Azuma, K. (2008) Predictors of Glycemic Control in Japanese Subjects with Type 2 Diabetes Mellitus. Metabolism—Clinical and Experimental, 57, 453-457. http://dx.doi.org/10.1016/j.metabol.2007.11.004

[17] Kellow, N.J., Savige, G.S. and Khalil, H. (2011) Predictors of Poor Glycaemic Control during the Initial Five Years Post-Diagnosis in Rural Adults with Type 2 Diabetes. Australian Journal of Rural Health, 19, 267-274. http://dx.doi.org/10.1111/j.1440-1584.2011.01222.x 